---مجلة علوم الرافدين، المجلد 27، العدد 4 / عدد خاص بالمؤتمر العلمي الثالث لعلوم الحياة، ص 95-102، 2018----

تمايز نباتات الترمس الابيض Lupinus albus من كالس السيقان تحت القلقية لبادراتها

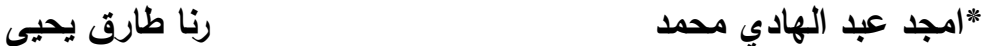

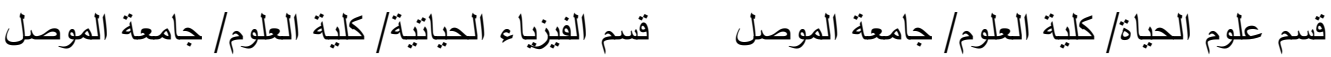

E-mail: biology19802007@yahoo.com*

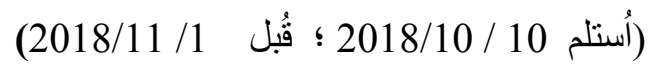

الملخص

نجحت الدراسة الحالية في الحصول على نباتات التزمس الأبيض Lupinus albus الكاملة من تمايز كالس السيقان تحت الفلقية لبادراتها المعقمة، وأوضحت النتائج تفوق وسط لتز في استحداثه للكالس بنسبة 90\% بعد 20 يوماً من الزراعة على غيره من الاوساط المنتخبة. وأعطى معدل قيم

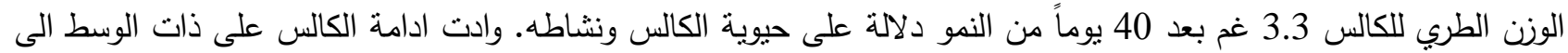

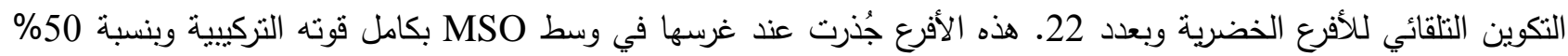
بعد 26 يوماً، منتجة نباتات الترمس الابيض الكاملة في الوسط الزرعي. الكلمات الدالة: نباتات الترمس الابيض، تمايز الكالس، الوزن الطري.

\title{
Regeneration of White Lupin, Lupinus albus, Plants form Hypocotyl Stems Callus of its Seedlings
}

\author{
Amjad A. Mohammed \\ Department of Biology / College of Science/ University of Mosul \\ Rana T. Yahya \\ Department of Biophysics/ College of Science/ University of Mosul
}

\begin{abstract}
This study succeeded in regenerating the white lupin, Lupinus albus, plants from differentiated the hypocotyl stems callus of its sterilized seedlings. The results indicated to superior the solid Murashige and Skoog (MS) medium provided with $1.0 \mathrm{mg} \mathrm{L}^{-1}$ NAA in callus initiation with $90 \%$ after 20 days of culture from the other of selected media. The rate of the value of the callus fresh weight was 3.3 gm after 40 days of growth, which gives indication on the viability and activity of callus. The continued of callus subculture on the same its initiated medium led to spontaneous production of 22 shoots. These regenerated shoots rooted when cultivated in MSO with its full strength at ratio $50 \%$ after 26 days, producing the whole lupin plants in the culture media.
\end{abstract}

Keywords : White lupin plants, callus differentiation, fresh weight.

\section{المقدمة}

تعد زراعة الانسجة النباتية من التقانات الحيوية ذات الاهمية البالغة، لما قدمته ولا زالت من فوائد مميزة على المستويين العلمي والنطبيقي في المجالات الزراعية والصناعية والصيدلانية والبيئية. وتوفر ايضاً نظاماً مميزاً لدراسة سلوك الخلايا (انسجة 
Seumann et al., ) كاملة او خلايا مفردة) وفهم علاقتها بمنظمات النمو من حيث انقساماتها وتخصصها الى نباتات كاملة 2009). و تعتمد هذه التقانة بشكل اساسي على عوامل عدة اهمها تزكيب الوسط الغذائي فضلا عن نوع وتركيز منظمات النمو المضافة اليه، وعليها يعتمد نجاح استمرار نمو الجزء النباتي المزروع على الوسط الغذائي، وافضل دليل هو فنثل محاولات العالم

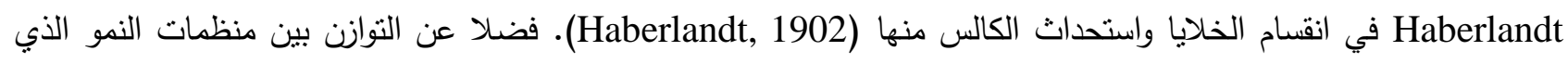
يملك دوراً بارزاً في استحداث الكالس من الاجزاء النباتية المختلفة وتمايز النباتات الكاملة منها (-1) Mohammed and Al .(Mallah, 2013 تتنمي نباتات التزمس Lupinus albus الى العائلة البقولية Fabaceae، وأصل نثأتها تعود الى جنوب شرق اوربا وغرب التي اسيا ومن ثم انتشرت زراعتها في اماكن مختلفة من العالم، ويعد من المحاصيل الثتوية ويوجد في جميع الاراضي خاصة الرملية

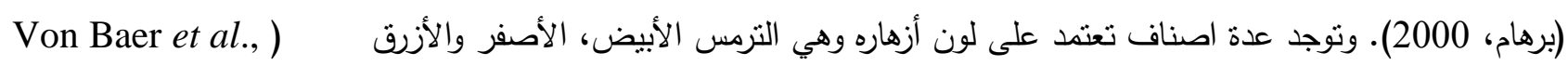

وتتاولت الدراسة صنف الترمس الابيض وهو نبات حولي، ويتميز بارتفاعه الذي يصل 100-20سم وله جذور قوية تمند عميقاً في التربة، وأوراقه متبادلة وكل نبات ينتج عدد من النورات، وازهاره بيضاء اللون وهي الصفة المميزة للنبات

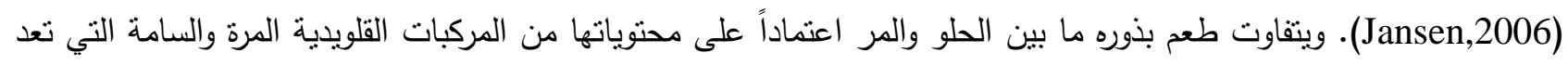

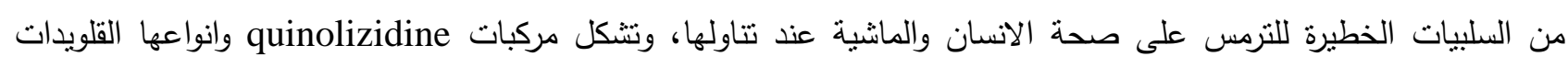

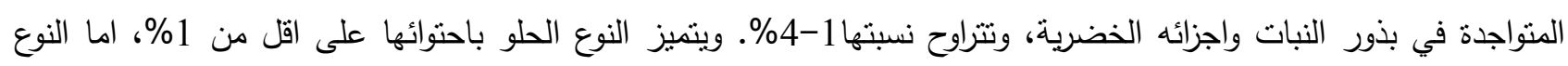
المر فيكون اكثر من ذلك (Bhardwaj and Hamama, 2012 ; Kurlovich et al., 2005). وللترمس فوائد غذائية للأنسان وكعلف للماشية لاحتوائه على نسبة عالية من البروتينات والدهون، كما بعد من المحاصيل الزيتية. وكذلك يملك فوائد صحية حيث ان البقوليات ومن ضمنها الترمس تحوي نراكيز عالية (اكثر من غرامين/كيلوغرام من الوزن الجاف) من المركبات الايزوفلافونيدية التي لها تأثير مضاد للسرطان (Sirtori et al., 2004). وفي المجال الزراعي استخدم لمدة طويلة في الولايات المتحدة كسماد

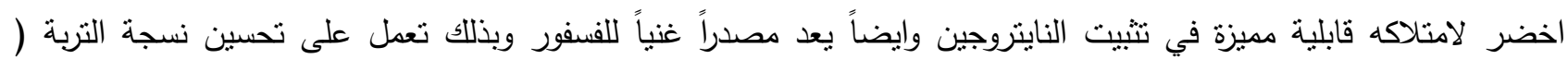
(Joseph et al., 2007 ; Agniszka et al., 2006 Sinha ( البروتوبلاست من اجزاء البادرات المختلفة باستخدام الطريقة الانزيمية وتميز البروتوبلاست المعزول بكثافة وحيوية عالية

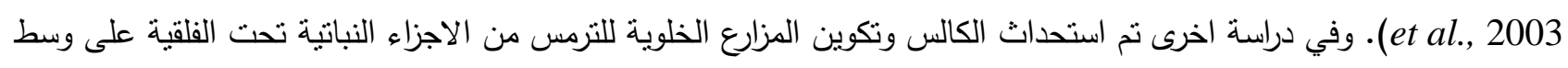
(Linsmaier and Skoog) LS

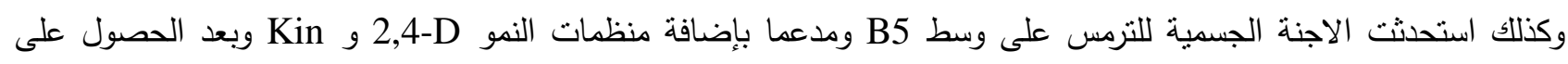

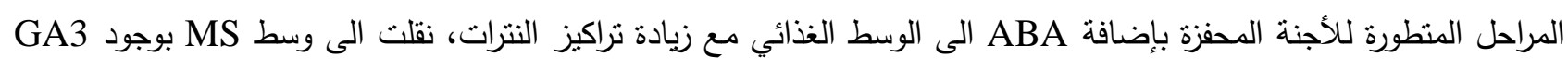
او الحامض الاميني الكلوتامين من اجل إنتاج النباتات الكاملة منها (Nadolska-Orczyk, 1992). ولندرة الدراسات على هذا النوع النباتي في مختبراتتا نسعى الدراسة الحالية الى ايجاد بروتوكول كفوء لاستحداث الناث الكالس

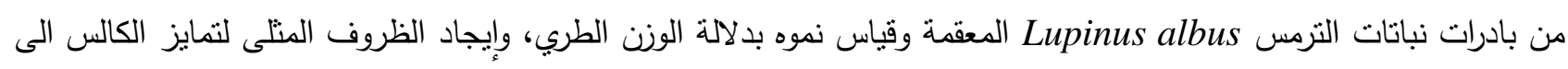
الافرع الخضرية وتجذيرها لإنتاج نباتات كاملة باستخدام منظمات النمو النباتية.

\section{المواد و طرائق العمل}

أجريت كافة التجارب في مختبر زراعة الأنسجة النباتية التابع لقسم علوم الحياة/كلية العلوم، وأنجزت عمليات تعقيم البذور

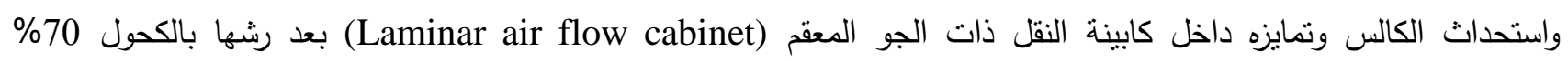


ومسحها بقطعة قطن معقمة وتشغيل الجهاز لنصف ساعة قبل البدء بالعمل، اما الاوساط الغذائية والماء المقطر والادوات فعقت بجهاز المعقام (Autoclave, Gallenkamp, U.K) في ظروف 121 درجة سيليزية وضغط 1.02 كغم /سم² لمدة 20 دقيقة. إنتاج بادرات الترمس المعقمة جهزت بذور نباتات الترمس الابيض Lupinus albus (النوع الحلو) من الاسواق المحلية / مدينة أربيل. وحددت نسبة أنباتها وبلغت 100\%، ثم غسلت بالماء الجاري للتخلص من الأثربة والأوساخ، وعقت سطحياً بغمرها في محلول الكحول الاثيلي 96 \% دقيقتين ثم في محلول هايبوكلورايت الصوديوم NaOCl (القاصر التجاري) والمخفف مع الماء المقطر المعق، قاصر :

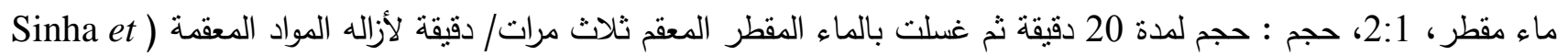

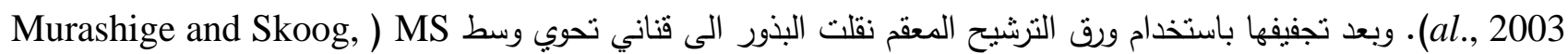
1962)، (الملحق) الصلب لوحده وبواقع بذرتين/ قنينة، وحفظت القناني في حاضنة النمو وبظروف الظلام وبدرجة حرارة 25 25 سيليزية. وبعد البدء بظهور الجذير والرويشة (التي استغرقت 7 ايام) نقلت القناني الى ظروف التعاقب الضوئي 16 ساعة ضوءهئه

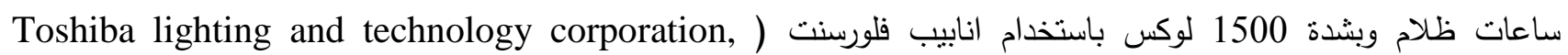
.(Tokyo, Japan تكوين مزارع الكالس

اخذت 1.0 سم تقريبا من قطع السيقان تحت الفلقية لبادرات التزمس وبعمر 20 يوما ووضعت بمعدل قطعتين/قنينة على سطح 30 مل من وسط MS الصلب لوحده (المقارنة) ثم مجهزاً بمنظمات النمو المنتخبة في هذه الدراسة ادناه: $\mathrm{NAA}^{1-}{ }^{-1.0+\mathrm{MS}}$ $\mathrm{NAA}^{1-}{ }^{-1-}$ ملغ $2.0+\mathrm{MS}$

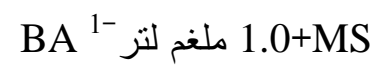
$\mathrm{BA}^{1-}$ 2.0+MS

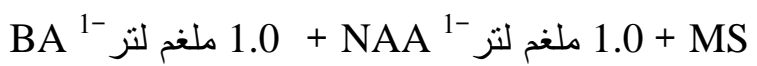

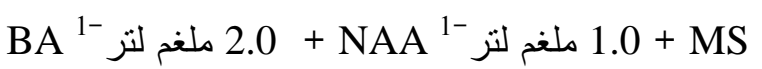
وبعد استحداث الكالس واختفاء معالم القطعة النبانية، النقطت كتل الكالس المتكونة ونقلت الى ذات الوسط واعيدت العطلية كل 20 يوم لتجنب نفاذ مكونات الوسط. وحفظت العينات كافة في ظروف نتمية البادرات. تكوين الافرع الخضرية من كالس السيقان وضعت قطعة من كالس السيقان بوزن 1.0 غم تقريبا وبعمر 20 يوما على سطح وسط MS الصنس الصلب والمدعم بإضافة

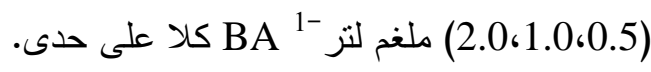

تجذير الافرع الخضرية استؤصلت الافرع الخضرية المتمايزة وبطول 1.5- 2.0 سم حاوية على 2-3 اوراق بواسطة مشرط معقم. وغرست قائمة في وسط MSO بكامل او نصف قوته التركييية كلا على حدى (العنزي، 2013) وحفظت العينات كما ذكر انفاً. الوزن الطري

حدد الوزن الطري للكالس النامي بأخذ الفرق بين وزن القناني وهي حاوية على الوسط الغذائي (وسط استحداث الكالس نفسه) فقط ووزنها بعد نقل الكالس عليها خلال مراحل النمو 20،40 بورماً. 


\section{امجد عبد الهادي محمد و رنا طارق يحيى \\ النتائج و المناقثة}

انتاج البادرات المعقمة

اظهرت نتائج طريقة التعقيم السطحي لبذور نباتات الترمس المستخدمة كفاءتها، بدلالة الحصول على بادرات سليمة مكتملة

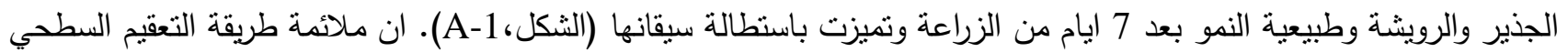

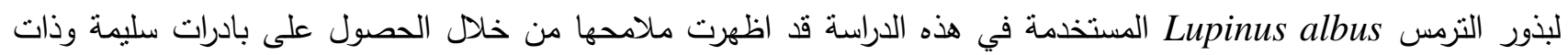
حيوية جيدة. ويعتمد استخدام المواد المعقمة المختلفة على وقت تعريض البذور لها فضلا عن تراكيزها والتي تعد من الاساسيات الحرجة لاستخدام تلك البذور لاحقا لأنتاج بادرات معقمة وسليمة وغير متضررة من عمليات التعقيم (Sen et al., 2013). تكوين مزارع كالس السيقان تحت الفلقية: ابدت قطع السيقان تحت الفقية تبايناً في استحداثها الكالس استتادا الى التباين في نوع وتركيز منظمات النمو المستخدمة

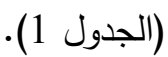

الجدول 1: نسبة استحداث كالس السيقان تحت القلقية لبادرات نباتات الترمس Lupinus albus على وسط MS الصلب مدعماً بإضافات من منظمات النمو NAA و

\begin{tabular}{|c|c|c|}
\hline مدة الاستحداث & الكالس (\% (\%) & (ملفم لتر -1) الاستحداث \\
\hline 0 & 0 & MSO \\
\hline 20 & 90 & NAA $1.0+\mathrm{MS}$ \\
\hline 33 & 30 & NAA $2.0+\mathrm{MS}$ \\
\hline 28 & 50 & $\mathrm{BA} 1.0+\mathrm{NAA} 1.0+\mathrm{MS}$ \\
\hline 30 & 60 & BA $2.0+\mathrm{NAA} 1.0+\mathrm{MS}$ \\
\hline
\end{tabular}

عدد القطع المزروعة 20 لكل معاملة

وتظهر النتائج الدور المميز لوسط MS المدعم بإضافة 1.0 ملغم لتز مAA لاستحداث الكالس بنسبة بلغت 90\% بعد

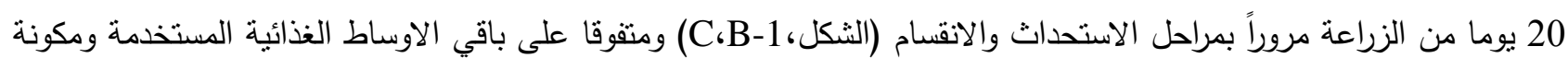

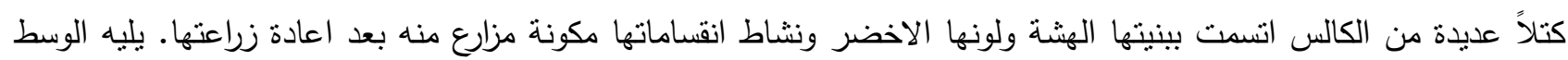

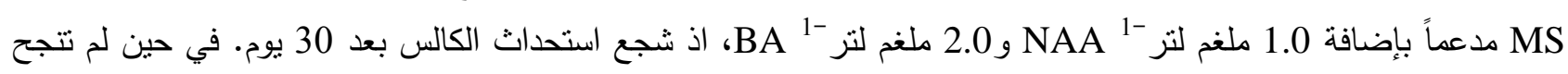

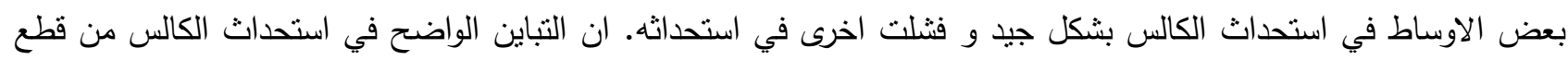
السيقان تحت الفلقية لبادرات التزمس يفسر بنباين منظمات النمو المنتخبة وتراكيزها (يحيى والصالح، 2013). وقد يرجح تفوق لوحده في الوسط الغذائي في استحداثه الكالس الى دور الاوكسينات في توسع الخلية من خلال تأثيره على ليونة الجدار

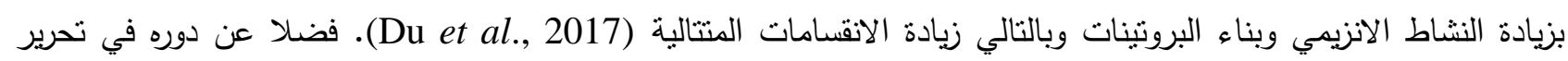

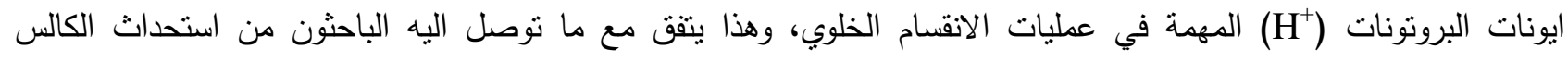

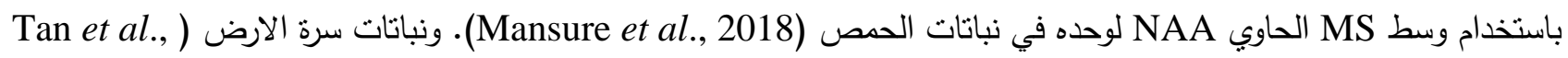




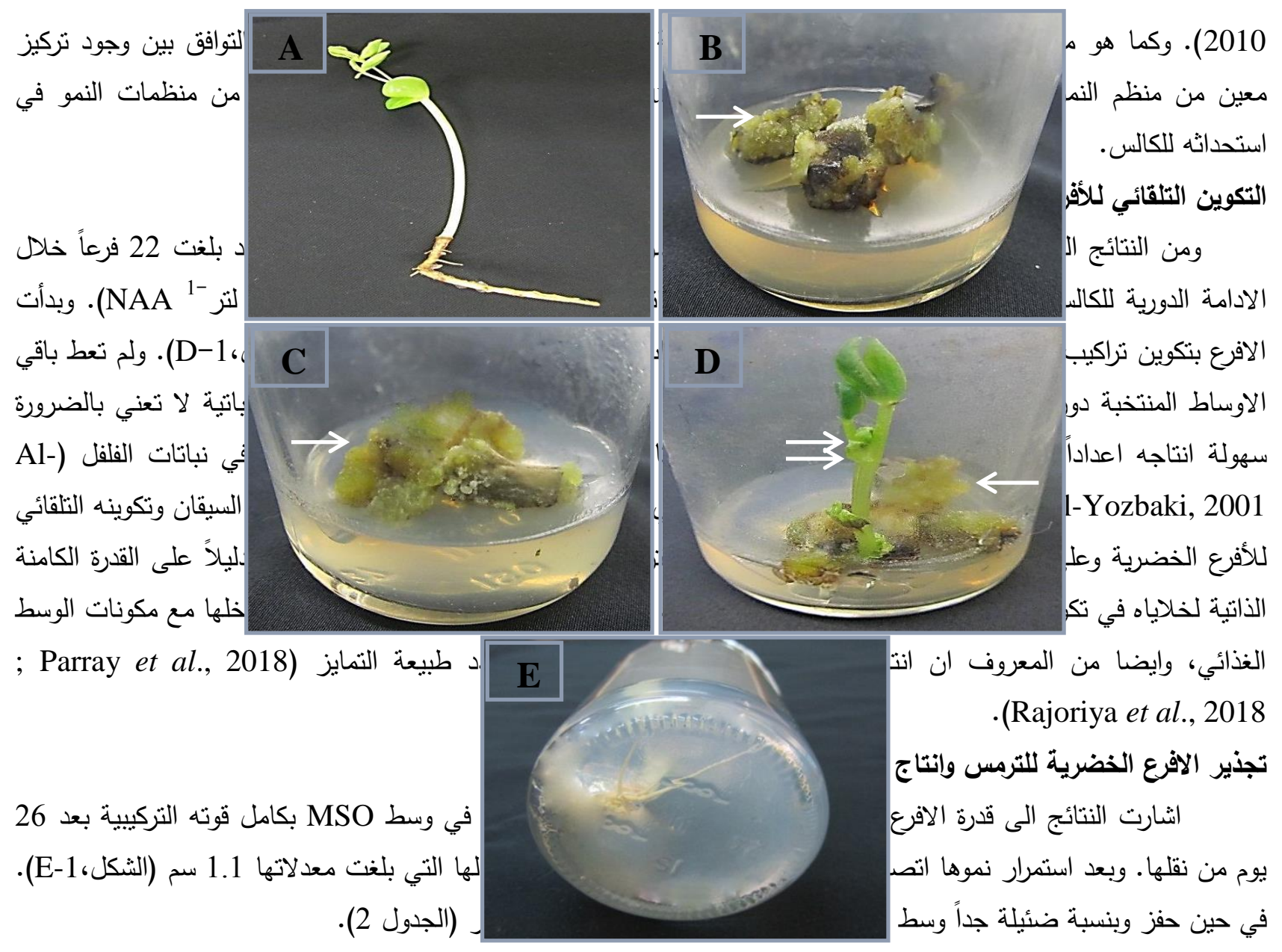

الجدول 2: تجذير الافرع الخضرية المتمايزة للترمس Lupinus albus في وسط MSO الصلب

\begin{tabular}{|c|c|c|c|}
\hline النسبة المئوية لتكوين الجذور & المدة الزمنية للتجذير (يوم) & المزروعة/المجذرة & الوسط الغذائي \\
\hline 50 & 26 & $5 / 10$ & MSO \\
\hline 10 & 36 & $1 / 10$ & MSO $1 / 2$ \\
\hline
\end{tabular}

ان اضافة منظمات النمو الى وسط الزراعة يعتمد على الغاية من الدراسة وعلى الجزء النباتي والنوع النباتي المستخدم التي تتتج طبيعياً الكميات التي تحتاجها من تلك المنظمات ولا تحتاج الى اضافات منها اذ من المحتمل ان تؤثز سلبا على نمو

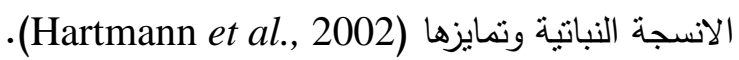


الثكل 1: تكوين مزارع كالس السيقان تحت القلقية لبادرات نباتات التزمس Lupinus albus وتمايزها الى نباتات كاملة في

\section{الوسط الزرعي}

(A)

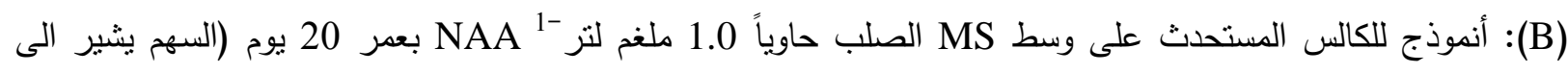

بداية اختفاء معالم القطعة النباتية)

(C): أنموذج أخر للكالس المستحدث على وسط MS الصلب حاوياً 1.0 ملغم لتر مAA الى اختفاء معالم القطعة النباتية بالكامل وازدياد نمو الكالس ومتجهاً لتكوين مزارعه)

(التكوين التلقائي للأفرع الخضرية بتمايزها من الكالس النامي على ذات الوسط في (C) وبعمر 25 يوماً (السهم المفرد

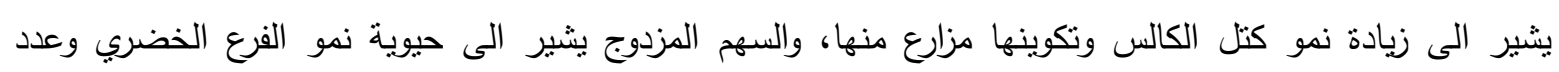
الوزن الطري للكالس:

اظهرت النتائج زيادة واضحة في معدلات الوزن الطري والتي بلغت 3.3 غم للكالس النامي على وسط MS الند بإضافة 1.0 ملغم لتر ${ }^{1-}$ NAA بعد 40 يوماً من النمو الثكل (2). ويعد الوزن الطري احدى المقاييس البايولوجية المهمة لنمو

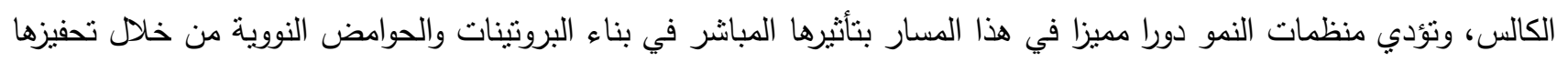

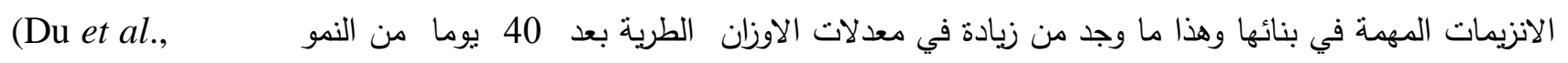




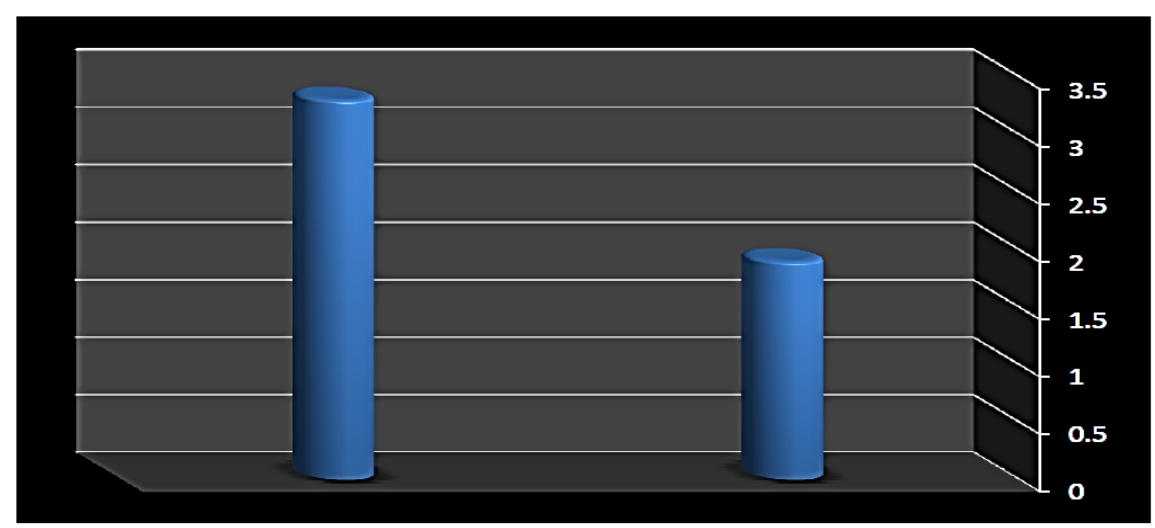

الشكل 2: الوزن الطري لكالس السيقان تحت القلقية لنباتات الترمس Lupinus albus بعد 20،40 يوماً من الزراعة على

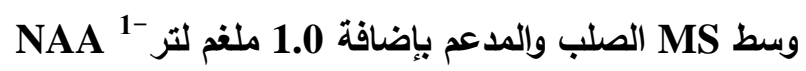
ت* * كل قراءة تمنل معدل 4 مكررات المصادر العربية

العنزي، امجد عبد الهادي محمد (2013). احتفاظ نباتات الجزر Daucus carota Lol-genes بمجموعة الناتجة من أنسجته المحولة وراثياً ببكتريا Agrobacterium rhizogenes R1601. اطروحة دكتوراه، كلية العلوم، جامعة الموصل.

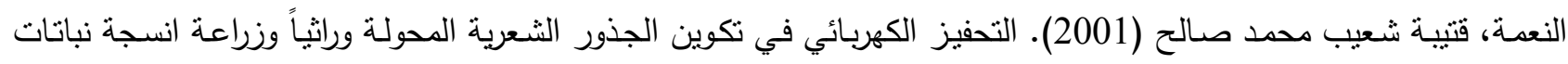
البنجر السكري (Beta vulgaris L.). رسالة ماجسنتر ، كلية التربية، جامعة الموصل.

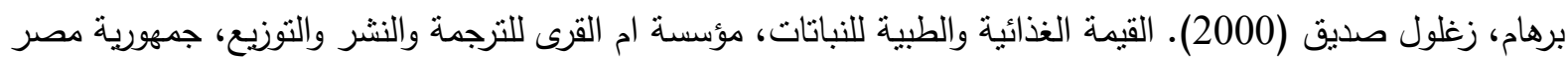
العربية.

يحيى، رنا طارق؛ الصالح، هناء سعيد (2013). استحداث ونمو مزارع الكالس من قطع السيقان والاوراق الفلقية لنبات الخرنوب Prosopis farcta L.

\section{المصادر الأجنبية}

Agniszka, A.; Anna, K.; Waclaw, W. (2006). Compositional and nutrition of several lupin seeds. Food Chemistry., 98,711-719.

AL-Mallah, M.K.; AL-Yozbaki, G.S. (2001). In vitro callus induction from Capsicum annum seedlings (sweet and chili pepper). J. Biotech. Res. 3, 34-44.

Bhardwaj, H.L.; Hamama, A.A. (2012). Cultivar and growing location effects on white lupin immature green seeds. J. Agricult. Sci., 4 (2), 135-138.

Du, H.; Ahmed, F.; Lin, B.; Li, Z.; Huang, Y.; Sun, G.; Ding, H.; Wang, C.; Meng, C.; Gao, Z. (2017). The Effects of plant growth regulators on cell growth, protein, carotenoid, PUFAs and lipid production of chlorella pyrenoidosa ZF strain. Energies., 10(11), 1-23.

Haberlandt, G. (1902). "Cultiversuchemit Isolierten Ptanzenzellen". Cited by Street, H.E. (1977). Plant Tissue and Cell Culture. Black Well Scientific Publication. Oxford. London. Edinburgh. Melbourne. 


$$
\text { امجد عبد الهادي محمد و رنا طارق يحيى }
$$

Hartmann, H.T.; Kester, D.E.; Davies, I.T.; Geveve, R.L. (2002). "Plant Propagation Principle and Practices". $7^{\text {th }}$ ed., Pearson Education، Inc., New York

Jansen, P.C.M. (2006). Lupinus albus L. Record from Protabase. Brink, M. and Belay, G. (Editors). PROTA (Plant Resources of Tropical Africa- Ressources végétales de l'Afrique tropicale), Wageningen, Netherlands.

Joseph, H.; Ralf, G.; Karim, A. (2007). Effect of instantaneous controlled pressure drop on the phytate content of lupin. Food Sci. Technol., 40 (3), 448-453.

Juan, L.; Lihua, W.; Jing, L.; Junhui, W. (2010). Effect of different plant growth regulators on callus induction in Catalpa bungei. Afric. J. Agri. Res., 5, 2699-2704.

Kurlovich, B.S.; Heinanen, J.; Kartuzova, L.T.; Bernatskaya, M.L.; Chmeleva, Z.V.; Berville, A. (2005). Diversity of (Lupinus L.) based on biochemical composition. Publie. Dans. le.,134, 42-57.

Mansur, R.M.; Alaila, A.K.; Mohamed, R.F.; Hamad, H.M.E. (2018). Effect of different plant growth regulators on callus induction from seeds of Chickpea (Cicer arietinum L.). Internat. J. Environment, Agricult. Biotech., 3(1), 99-102.

Mohammed, A.A.; Al-Mallah, M.K. (2013). Determination of $\beta$-carotene in Carrot (Daucus carota L.) plants regenerated from stems callus. Raf. J. Sci., 24(3), 27-36.

Murashige, T.; Skoog, F. (1962). A revised medium for rapid growth and bioassays with tobacco tissue cultures. Physiol. Plant., 15, 473-497.

Nadolska-Orczyk, A. (1992). Somatic embryogenesis of agriculturally important lupin species (Lupinus angustifolius, L. albus, L. mutabilis). Plant Cell, Tiss. Org. Cult., 28 (1), 19-25.

Neumann, K.; Kumar, A.; Imani, J. (2009). "Plant Cell and Tissue Culture - A tool in Biotechnology". Springer-Verlag Berlin, Germany.

Parray, J.A.; Kamili, A.N.; Jan, S.; Mir, M.Y.; Shameem, N.; Ganai, B.A.; Abd_Allah E.F.; Hashem, A.; Alqarawi, A.A. (2018). Manipulation of plant growth regulators on phytochemical constituents and DNA protection potential of the medicinal plant Arnebia benthamii. Bio. Med. Res. Internat., 1-8. Open access.

Rajoriya, P.; Singh, V.K.; Jaiswal, N.; Lall, R. (2018). Optimizing the effect of plant growth regulators on in vitro micro propagation of Indian red banana (Musa acuminata). J. Pharmacognosy and Phytoch., 1, 628-634.

Sen, M.K.; Jamal, M.A.M.; Nasrin, S. (2013). Sterilization factors affect seed germination and proliferation of Achyranthes aspera cultured in vitro. Environment Experiment Biol., 11, 119-123.

Sinha, A.; Wetten, A.C.; Caligari, P.D.S. (2003). Effect of biotic factors on the isolation of Lupinus albus protoplasts. Austral. J. Bot., 51, 103-109.

Sirtori, C.R.; Lovati, M.R.; Manzoni, C.; Castiglioni, S.; Duranti, M.; Magni, C.; Morandi, S.; D'Agostina, A.; Arnoldi, A. (2004). Proteins of white lupin seed, a naturally isoflavone-poor legume, reduce cholesterolemia in rats and increase LDL receptor in HepG2 cells. J. Nutr. Jan, 134 (1), 18-23.

Sroga, G.E. (1983). Callus and suspension culture of Lupinus angustifolius cv. Turkus. Plant Sci. Letters., 32 (1-2), 183-192

Tan, S.H.; Musa, R.; Ariff, A.; Maziah, M. (2010). Effect of plant growth regulators on callus, cell suspension and cell line selection for flavonoid production from Pegaga (centella asiatica $\mathrm{L}$. urban). American J. Biochem. Biotech., 6 (4), 284-299.

Von Baer, E.; Von Baer, I.; Riegel, R. (2009). Pecosa-Baer: A new cultivar of white lupin with determined bushy growth habit, sweet grain and high protein content. Chilean J. Agri. Res., 69, 577-580. 